\title{
Effects of Piston Bowl Diameter on Combustion Characteristics of a Natural gas/Diesel Dual Fuel Engine
}

\section{$\operatorname{AUTHOR}(S):$}

Takizawa, Keigo; Tanaka, Hidetake; Horibe, Naoto; Ishiyama, Takuji; Sako, Takahiro

\section{CITATION:}

Takizawa, Keigo ... [et al]. Effects of Piston Bowl Diameter on Combustion Characteristics of a Natural gas/Diesel Dual Fuel Engine. SAE Technical Paper 2019: Technical Paper201901-2173.

\section{ISSUE DATE:}

2019-12-19

URL:

http://hdl.handle.net/2433/251432

\section{RIGHT:}

This is the accepted manuscript of the article, which has been published in final form at https://doi.org/10.4271/201901-2173.; The full-text file will be made open to the public on $19 \mathrm{June} 2020$ in accordance with publisher's 'Terms and Conditions for Self-Archiving'; この論文は出版社版でありません。引用の際には出版社版をご確認ご利用ください。; This is not the published version. Please cite only the published version. 


\title{
Effects of Piston Bowl Diameter on Combustion Characteristics of a Natural gas/Diesel Dual Fuel Engine
}

\author{
Keigo Takizawa, Hidetake Tanaka, Naoto Horibe, Takuji Ishiyama \\ Kyoto University
}

Takahiro Sako

Osaka Gas Co., Ltd.

Copyright $\odot 2019$ SAE Japan and Copyright $\odot 2019$ SAE International

\begin{abstract}
Natural gas/diesel dual fuel engines have potential for a high thermal efficiency and low NOx emissions. However, they have the disadvantages of high unburned species emissions and lower thermal efficiencies at low loads (at low equivalence ratio). A way to solve this problem is to properly distribute the pilot fuel vapor in a natural-gas premixture. The combustion chamber geometry affects the combustion process since it influences the distribution of the pilot fuel vapor. This study investigates the influence of injection conditions and the piston bowl geometry on the performance and emissions of a dual fuel engine. Experiments were carried out using two pistons with different bowl diameters, $52 \mathrm{~mm}$ and $58 \mathrm{~mm}$, at singleand two-stage diesel-fuel injection. The results show that the larger bowl provides lower hydrocarbon emissions at a lower equivalence ratio in the case of single-stage injection. For two-stage injection, the influence of the bowl diameter depends on the timing of the first injection. To elucidate the effects of pilot fuel distribution, computational fluid dynamics (CFD) calculations were conducted for non-reacting pilot fuel sprays under conditions equivalent to the experiments. As a result, the relative rich area of the pilot fuel in the case of the single injection in the large piston bowl do not impinge on the piston wall at the ignition timing of the experiment, which leads to higher heat release rate owing to the weak cooling effect.
\end{abstract}

\section{INTRODUCTION}

In natural gas/diesel dual fuel engines, a lean natural gas/air premixture is ignited by the combustion of a pilot diesel-fuel spray. They have the potential for high thermal efficiency and low NOx emissions. Natural gas/diesel dual fuel engines have been investigated as an alternative to heavy-duty diesel engines, and a higher thermal efficiency than spark-ignition engines has been achieved [1, 2].

Under high load conditions, the thermal efficiency by dual fuel operation is equivalent to that of a diesel engine. Under low and medium load conditions, however, the thermal efficiency is low and unburned emission is high due to the low combustion efficiency $[3,4]$.

In the dual fuel operation mode, the distribution of the diesel spray influences the flame propagation of the natural gas/air premixture. Therefore, pilot injection conditions and combustion chamber geometry are the most important factors in order to solve the above problem under low load conditions.

Many researchers have investigated the influence of pilot injection on engine performance in the dual fuel operation. For example, Tomita et al. [5] varied the injection timing over a wide range for a single-cylinder naturally-aspirated engine fueled with pure methane. A very early injection $\left(-50^{\circ} \mathrm{ATDC}\right)$ was demonstrated to improve the NOx-total hydrocarbon (THC) tradeoff relation without decreasing the thermal efficiency.

Aroonsrisopon et al. [6] investigated the use of a multiple direct injection strategy for improvement of low load dual fuel operation. The results indicate a large quantity; thus, early first injection $\left(-50^{\circ}\right.$ ATDC) is effective for improvement of the performance and reduction of exhaust emissions. In our previous study [7], two-stage pilot injection also offers improved thermal efficiency and reduced exhaust emissions when early first injection ( -45 to $-40^{\circ}$ ATDC) and moderately early second injection are selected.

Combustion chamber geometry is also an important factor for the control of the distribution of diesel fuel. Amir-Hasan et al. [8] numerically investigated the effects of three different geometries on the natural gas/diesel reactivity controlled compression ignition (RCCl) performance and emissions at medium engine load. They found that the bowl profile does not affect the combustion of an $\mathrm{RCCl}$ engine at low engine speed, but has a considerable effect at higher engine speed. They also showed that the bathtub design yields the 
best performance and emissions at higher speed.

In our previous study [9], Kang used combustion chambers with diameters of 56,68 , and $80 \mathrm{~mm}$ in a natural gas/diesel dual fuel engine. It was revealed that a larger bowl diameter provides lower THC and $\mathrm{CO}$ emissions at earlier pilot injection timings in the singlestage injection mode. In the case of two-stage pilot injection, the larger bowl diameter reduced the THC and NOx emissions for a smaller amount of first injection, while having a weak influence on the exhaust emissions for a larger amount of first injection.

As these papers indicate, the combustion chamber geometry is an influencing factor of engine performance. However, in these papers, the size of the squish area changed due to a large change in the shape of the combustion chambers. Therefore, the squish flow changed greatly, the strength and distribution of turbulence was considered to have influenced the distribution of diesel fuel and the combustion of natural gas, and it was difficult to organize the influence on the performance and emissions. In order to develop a strategy for the design of combustion chamber geometry, it is necessary to consider the influence of the combustion chamber geometry on the engine performance over a wide load range and to elucidate the relationship between pilot fuel distribution and combustion in dual fuel engines.

In this study, in order to clarify the influence of combustion chamber geometry (spray collision distance) on performance and exhaust, the piston bowl diameter was moderately changed with an engine which has a relatively large squish height. The effects of the combustion chamber diameter and the injection conditions were investigated using a single-cylinder natural gas/diesel dual fuel engine with a bore of 88 $\mathrm{mm}$. The chambers used in this study were $52 \mathrm{~mm}$ and $58 \mathrm{~mm}$, and the injection timings were changed for single-stage and two-stage injection. Furthermore, a CFD simulation was conducted in order to elucidate the effects of the combustion chamber shape on the pilot fuel distribution, and the effects on combustion in the experiments are discussed based on the calculated results.

\section{EXPERIMENTAL SETUP}

\section{BASIC CHARACTERISTICS OF DUAL FUEL ENGINE EXPERIMENT}

In this study, the engine used for the experimental investigation was a single-cylinder, four-cycle engine. Its major specifications are listed in Table 1. The bore and stroke were $88 \mathrm{~mm}$ and $84 \mathrm{~mm}$, respectively. The compression ratio was 12.5 , and the combustion chamber is toroidal type. To supply the pilot fuel, the engine is equipped with an electrically controlled common-rail injection system. The high-pressure supply pump was driven by an electric motor. The injector was a solenoid-actuated type with six holes of $0.12 \mathrm{~mm}$. JIS No.2 diesel fuel (cetane index 55) was used as the pilot fuel.
Table 1 Engine specifications

\begin{tabular}{|l|c|}
\hline Engine type & $\begin{array}{c}\text { Natural gas/diesel dual fuel } \\
\text { engine, single-cylinder, water- } \\
\text { cooled }\end{array}$ \\
\hline Bore $\times$ Stroke & $88 \mathrm{~mm} \times 84 \mathrm{~mm}$ \\
\hline Displacement & $511 \mathrm{~cm}^{3}$ \\
\hline Compression ratio & 12.5 \\
\hline $\begin{array}{l}\text { Combustion } \\
\text { chamber }\end{array}$ & Toroidal type \\
\hline Number of valves & 1 intake and 1 exhaust \\
\hline Intake charging & External supercharging \\
\hline $\begin{array}{l}\text { Pilot fuel injection } \\
\text { system }\end{array}$ & $\begin{array}{c}\text { Common-rail system } \\
0.12 \mathrm{~mm} \times 6 \text { holes } 140^{\circ} \text { nozzle }\end{array}$ \\
\hline Main fuel supply & $\begin{array}{c}\text { Continuous supply } \\
\text { into an intake pipe }\end{array}$ \\
\hline
\end{tabular}

Figure 1 shows the experimental setup. The intake system was an external supercharging system. The main fuel, Japanese 13A natural gas, was continuously supplied into the intake pipe $300 \mathrm{~mm}$ upstream from the cylinder head. The mass flow rate was adjusted by a mass flow controller. The composition and the lower heating value of the natural gas are listed in Table 2.

The geometry of the two combustion chambers and the direction of the pilot fuel spray are shown in Figure 2. The piston bowl diameters of the combustion chamber D52A and D58A were $52 \mathrm{~mm}$ and $58 \mathrm{~mm}$, respectively. The compression ratio, piston bowl volume, the crevice height, and squish height of the pistons were not changed. Therefore, the depth of D58A was smaller than that of D52A. Although the turbulence by the squish was changed, the change would be small because the squish height was larger than usual. The piston positions for several crank angles are also illustrated for reference. The spray direction for D52A targeted the piston bowl edge between $-35^{\circ}$ to $-30^{\circ}$ ATDC, while the spray direction for D58A already targeted the inner surface of the cavity at $-40^{\circ}$ ATDC.

Table 2 Volumetric fraction of the main species within the natural gas and lower heating value

\begin{tabular}{|l|c|}
\hline Methane $\left(\mathrm{CH}_{4}\right)$ & $89.62 \%$ \\
\hline Ethane $\left(\mathrm{C}_{2} \mathrm{H}_{6}\right)$ & $5.62 \%$ \\
\hline Propane $\left(\mathrm{C}_{3} \mathrm{H}_{8}\right)$ & $3.43 \%$ \\
\hline Butane $\left(\mathrm{C}_{4} \mathrm{H}_{10}\right)$ & $1.35 \%$ \\
\hline \hline Lower heating value & $43.5 \mathrm{~kJ} / \mathrm{g}$ \\
\hline
\end{tabular}




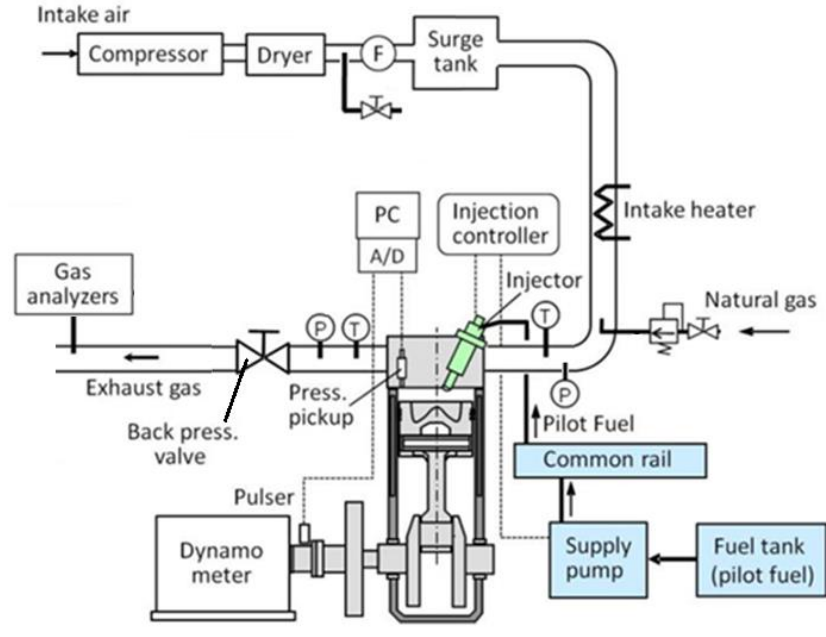

Fig.1 Experimental setup
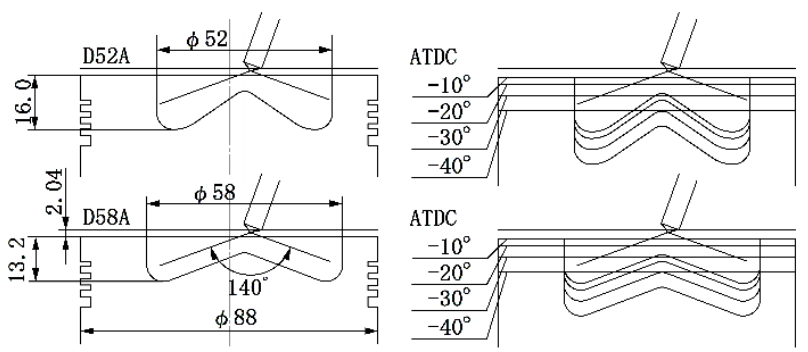

Fig.2 Combustion chamber and spray direction

\section{TEST CONDITIONS}

Table 3 shows the experimental conditions. All measurements were conducted at thermal steady states of the engine at a fixed speed of $1,200 \mathrm{rpm}$, an inlet coolant water temperature of $80^{\circ} \mathrm{C}$, and a lubricating oil temperature of $70^{\circ} \mathrm{C}$. The intake air temperature was $40^{\circ} \mathrm{C}$ and the intake air pressure was $180 \mathrm{kPa}$. The exhaust pressure was balanced with the intake pressure. The pilot injection quantity for single diesel-fuel injection was $5 \mathrm{~mm}^{3} /$ cycle. For two stageinjection, the first injection quantity was $3 \mathrm{~mm}^{3} /$ cycle and the second was $2 \mathrm{~mm}^{3} /$ cycle. When natural gas wasn't supplied, the equivalence ratio was 0.07 .

The natural gas flow rate was controlled by a mass flow meter. The flow rate was limited to limit the THC emissions to $10,000 \mathrm{ppmC}$ and the maximum incylinder pressure to $10 \mathrm{MPa}$.

The THC and $\mathrm{CO}$ concentrations were measured with a heated flame ionization detector THC analyzer (Horiba MEXA-1160TFI-H) and a non-dispersive infrared analyzer (R-Science RSIR-1200), respectively. The NOx emissions were measured using a chemiluminescent analyzer (Nippon Thermo MODEL42iHL). The in-cylinder pressure was measured by a piezoelectric pressure sensor (Kistler $6052 \mathrm{~A}$ ), and the average pressure for 50 cycles was used to calculate the heat release rate.
Table 3 Test conditions

\begin{tabular}{|c|c|c|}
\hline \multicolumn{2}{|l|}{ Engine speed } & $1,200 \mathrm{rpm}$ \\
\hline \multicolumn{2}{|c|}{ Coolant water temperature } & $80^{\circ} \mathrm{C}$ \\
\hline \multicolumn{2}{|l|}{ Lubricant temperature } & $70^{\circ} \mathrm{C}$ \\
\hline \multicolumn{2}{|l|}{ Intake air temperature } & $40^{\circ} \mathrm{C}$ \\
\hline \multicolumn{2}{|l|}{ Intake air pressure } & $180 \mathrm{kPa}$ \\
\hline \multicolumn{2}{|l|}{ Charging efficiency } & 1.44 \\
\hline \multicolumn{2}{|l|}{ Injection pressure } & $80 \mathrm{MPa}$ \\
\hline \multirow{2}{*}{ Pilot injection quantity } & Single & $5 \mathrm{~mm}^{3} /$ cycle \\
\hline & Two-stage & $3+2 \mathrm{~mm}^{3} /$ cycle \\
\hline
\end{tabular}

\section{CFD CALCULATION}

In order to examine the pilot fuel distribution, a CFD simulation was conducted using AVL FIRE v2013.2. Table 4 shows the major sub-models. The k-zeta-f model was used for the turbulence model, and the liquid phase was simulated by the Discrete Droplet model. The spray breakup was modeled by the KH-RT model $\left(C_{1}=0.61, C_{2}=12\right)$. The evaporation was modeled by the Dukowicz model. In this study, the nonreaction spray was calculated for the purpose of determining the diesel fuel vapor distribution. The calculation mesh was prepared according to the geometrical parameters of the actual engine, as shown in Figure 3. The start of the calculation was $-80^{\circ}$ ATDC and the end was $20^{\circ}$ ATDC. The time step after the injection was $0.1^{\circ} \mathrm{CA}$.

Table 5 shows the calculation conditions. The incylinder pressure and temperature were set to approximately the same as the experimental value. The spray half-cone angle was set to $9^{\circ}$.

Table 4 Sub-models of CFD simulation

\begin{tabular}{|l|c|}
\hline Turbulence & k-zeta-f \\
\hline Liquid phase & Discrete Droplet \\
\hline Spray breakup & KH-RT $(\mathrm{C} 1=0.61, \mathrm{C} 2=12)$ \\
\hline Evaporation & Dukowicz \\
\hline Combustion & Non \\
\hline
\end{tabular}

Table 5 Calculation conditions

\begin{tabular}{|l|c|}
\hline Initial temperature $\left(-80^{\circ} \mathrm{ATDC}\right)$ & $442 \mathrm{~K}$ \\
\hline Initial pressure $\left(-80^{\circ} \mathrm{ATDC}\right)$ & $0.39 \mathrm{MPa}$ \\
\hline Swirl ratio & 2.8 \\
\hline Fuel & DIESEL \\
\hline Half-cone angle & $9^{\circ}$ \\
\hline
\end{tabular}

In our previous study [10], it was found that the spray cone angle of the small-quantity injection was wider than that of the quasi-steady-state injection. In this study, the spray cone angle was adjusted to reproduce the spray behavior of the small-quantity injection in a high-pressure and high-temperature constant volume vessel. Figure 4 shows the shadowgraph images of the sprays. In this experiment, a six-hole injector, with 
holes of $0.18 \mathrm{~mm}$ in diameter, was used. The fuel used was JIS No.2 diesel fuel, the quantity of which was 2.5 $\mathrm{mg}$. The injection pressure was $130 \mathrm{MPa}$, and the ambient conditions were $4 \mathrm{MPa}$ and $1015 \mathrm{~K}$ with no oxygen. Although the injection conditions were not the same as those of the engine experiments, the data were referenced due to a lack of multi-hole injector data. Figure 5 shows the spray tip penetration and spray angle of the sprays in Figure 4 and those of the CFD simulation with varying spray cone angles. It indicates that the CFD result with a half-cone angle of $9^{\circ}$ seems to reproduce the spray tip penetration and spray angle of the experimental results. Therefore, the half cone angle was set to $9^{\circ}$ in this study.

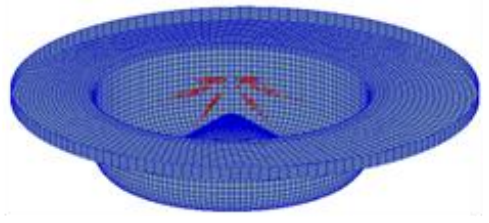

(a)

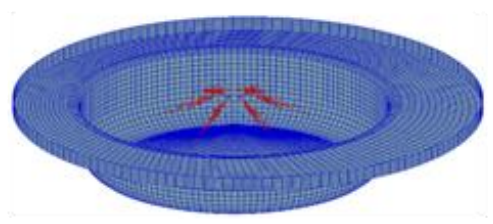

(b)

Fig.3 Mesh for calculation (a) D52A (b) D58A

$0.04 \mathrm{~ms} \quad 0.08 \mathrm{~ms} \quad 0.12 \mathrm{~ms} \quad 0.16 \mathrm{~ms} \quad 0.20 \mathrm{~ms} \quad 0.24 \mathrm{~ms}$

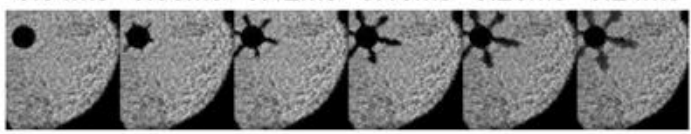

$0.28 \mathrm{~ms} \quad 0.32 \mathrm{~ms} \quad 0.36 \mathrm{~ms} \quad 0.40 \mathrm{~ms} \quad 0.44 \mathrm{~ms} \quad 0.48 \mathrm{~ms}$

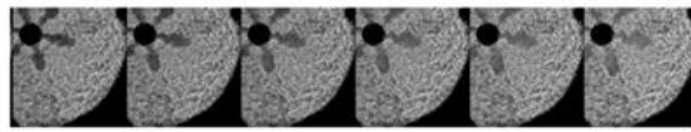

$0.52 \mathrm{~ms} \quad 0.56 \mathrm{~ms} \quad 0.60 \mathrm{~ms} \quad 0.64 \mathrm{~ms} \quad 0.68 \mathrm{~ms} \quad 0.72 \mathrm{~ms}$

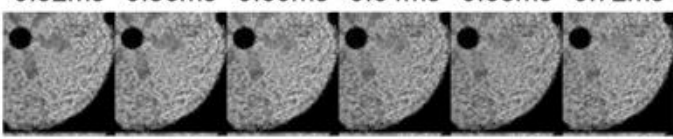

$0.76 \mathrm{~ms} \quad 0.80 \mathrm{~ms} \quad 0.84 \mathrm{~ms} \quad 0.88 \mathrm{~ms} \quad 0.92 \mathrm{~ms} \quad 0.96 \mathrm{~ms}$

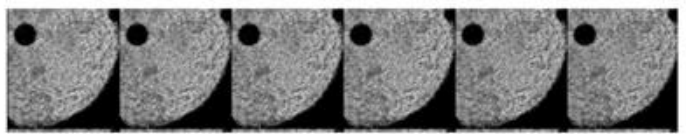

Fig.4 Shadowgraph images of sprays with smallquantity in a constant volume vessel (inj. quantity $=2.5 \mathrm{mg}$, inj. pressure $=130 \mathrm{MPa}$, initial ambient temperature $=1015 \mathrm{~K}$, initial ambient pressure $=4 \mathrm{MPa}$ )

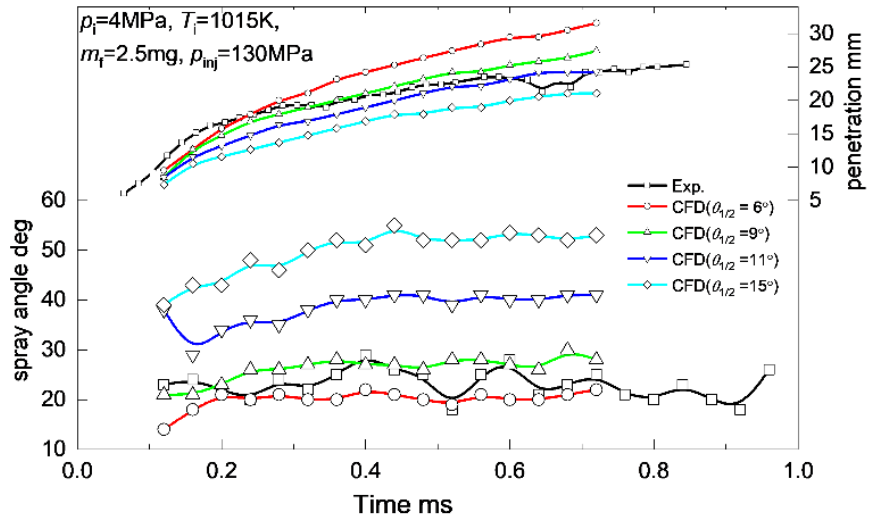

Fig.5 Spray tip penetration and spray angle of CFD and experimental results

\section{RESULTS AND DISCUSSION}

\section{SINGLE INJECTION}

In order to investigate the basic characteristics of the engine performance using two combustion chamber geometries with the single injection strategy, the experiments with single injection (injection quantity $q_{1}$ $=5 \mathrm{~mm}^{3} /$ cycle) were conducted while varying the total equivalence ratio $\phi$. The pilot injection timings $\theta$ were set to $-15^{\circ}$ and $-5^{\circ}$ ATDC as the early and late injection timings, respectively. Figure 6 shows the indicated mean effective pressure (IMEP) $p_{i}$, the indicated thermal efficiency $\eta$, the coefficient of variation (COV) of the IMEP $\delta_{\mathrm{pi}}$, and the THC and NOx emissions against the total equivalence ratio $\phi$. Under relatively high $\phi_{t}(>0.4)$ conditions, the combustion chamber did not significantly affect the performance and emissions for either injection timings. In contrast, under relatively low $\phi_{t}(<0.4)$ conditions, D58A provided lower THC emissions and higher $\eta_{\mathrm{i}}$ compared to D52A.

For the sake of examining the above tendency, a combustion analysis was conducted. Figure 7 shows the in-cylinder pressure and the heat release rate of the low and high $\phi_{t}$. In the case of a high $\phi_{t}$ (Fig. 7, right), the heat release rates of both combustion chambers were almost the same. Three peaks of the heat release rate appeared, namely, a low heat release rate by the low temperature reaction of the diesel fuel around $-8^{\circ}$ ATDC, a rapid heat release rate (called "initial combustion" in [3]) stimulated by the pilot-spray ignition just before TDC, and a following broad heat release rate mainly by the combustion of the natural gas (called "main combustion" in [3]). It is supposed that the equivalence ratio of the natural gas premixture was rich enough for flame propagation to occur. Therefore, the combustion chamber did not significantly affect the performance and emissions. Meanwhile, in the case of a low $\phi_{\mathrm{t}}$ conditions (Fig. 7, left), the heat release rate of the initial combustion cannot be separated from that of the main combustion. The ignition timing is almost the same between the two combustion chambers; however, the gradient of the heat release rate of D58A was apparently higher than that of D52A. This means more natural gas of D58A was used for combustion. Therefore, THC emissions of D58A is less than that of D52A. 
Comparing the high and low $\phi_{t}$, the ignition timing of the lower $\phi$ was later. This is probably because the incylinder gas temperature was lower due to the lower temperatures of the combustion chamber wall and residual gas. The lower in-cylinder temperature would foster the difference of the engine performance and the heat release rate at the low $\phi$.

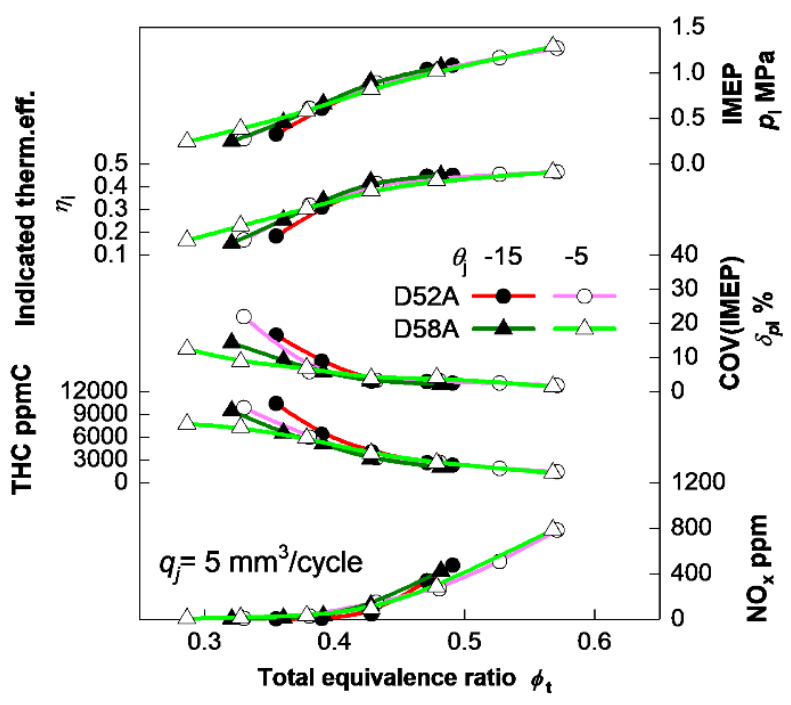

Fig.6 Performance and emissions against $\phi_{\mathrm{t}}$ (single injection, $\left.\theta_{\mathrm{j}}=-15,-5^{\circ} \mathrm{ATDC}\right)$

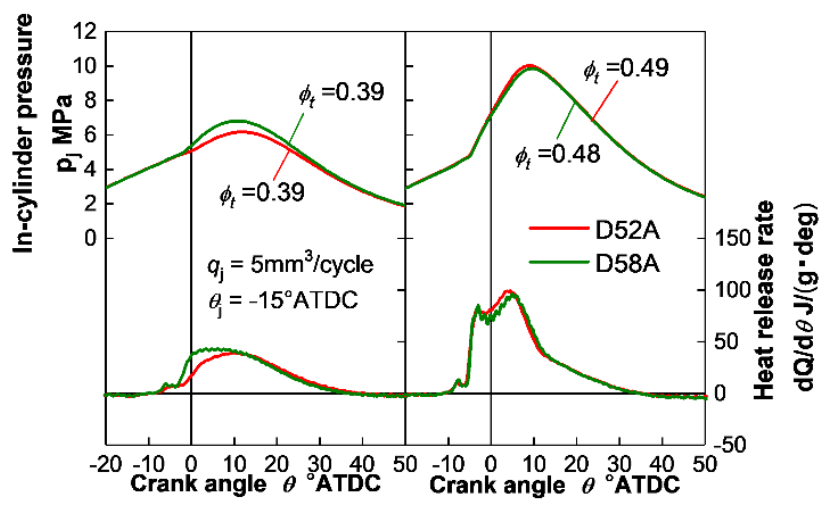

Fig.7 In-cylinder pressure and heat release rate (single injection, $\left.\theta_{3}=-15^{\circ} \mathrm{ATDC}\right)$

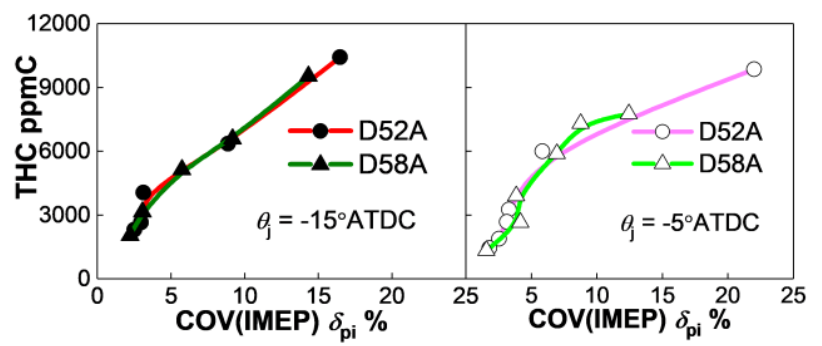

Fig.8 Relationship between $\delta_{\mathrm{pi}}$ and THC (single injection)
Cycle variation frequently relates to $\mathrm{THC}$ emission because the cycles with insufficient heat release are included when the cycle variation is heavy. Figure 8 shows the relationship between the $\delta_{\mathrm{pi}}$ and THC emissions for D58A and D52A. As the $\delta_{\mathrm{pi}}$ increased, the THC increased; the data of D58A and D52A show the same trend. This means that the lower THC emissions of D58A come from the reduced cycle variation at the same equivalence ratio.

\section{TWO-STAGE INJECTION}

Dividing the pilot fuel injection into two stages could improve the performance and emissions [6]. In this respect, to investigate the effect of the combustion chamber geometry on the performance and emission for two-stage injection, an experiment of two-stage injection was performed by varying the total equivalence ratio $\phi$.

Figure 9 shows the performance and exhaust emissions against the total equivalence ratio $\phi$ for the first and second pilot fuel quantities of $3 \mathrm{~mm}^{3}$ and 2 $\mathrm{mm}^{3}$, respectively (denoted as $q_{1} / q_{2}=3 / 2$ ). The first injection timings $\theta_{1}$ were $-30^{\circ}$ ATDC and $-40^{\circ}$ ATDC. The second injection timing $\theta_{2}$, in Fig.9(a), was $-15^{\circ}$ ATDC and $\theta_{2}$, in Fig. $9(\mathrm{~b})$, was $-5^{\circ}$ ATDC. At a $\phi_{t}$ higher than 0.5 , the differences in the IMEP, $\eta_{i}$, and THC between D58A and D52A were very small regardless of the injection timings, while the NOx emissions of D58A were much higher compared to D52A in the case of $-5^{\circ} \mathrm{ATDC}$ second injection timing.

The effects of the combustion chamber and injection timings were very complicated under low equivalence ratio conditions. In the case of $\theta_{1}=-30^{\circ}$ ATDC and $\theta_{2}$ $=-15^{\circ} \mathrm{ATDC}$, D58A provided lower $\mathrm{THC}$ emissions and a higher $\eta_{i}$ compared to D52A. This is the same tendency as the single injection case. However, in the case of other injection timings, the opposite tendency was shown, namely D58A provided higher THC compared to D52A.

To reveal the reasons for the opposite tendency between the two combustion chamber geometries with two-stage pilot injection, we focused on the cases of $\theta_{1}=-30^{\circ}$ ATDC. Figure 10 shows the relationship between the THC and COV of the IMEP $\delta_{\text {pi }}$. For $\theta_{2}=$ $-15^{\circ}$ ATDC, both combustion chambers show a similar trend. This indicates that the difference in the THC is caused by the $\delta_{\mathrm{pi}}$. Whereas, for the same $\delta_{\mathrm{pi}}$, the THC emissions of D52A were lower than that of D58A for $\theta_{2}$ $=-5^{\circ} \mathrm{ATDC}$.

In order to consider the complicated effects of the combustion chamber geometry and the injection timings, the in-cylinder pressure and the heat release rate for a relatively low total equivalence ratio $\phi_{t}$ are shown in Figure 11. In Figure 11 left, the gradient of the heat release rate of D58A is steeper at $\theta_{1}=$ $-30^{\circ}$ ATDC and $\theta_{2}=-15^{\circ} \mathrm{ATDC}$. This characteristic is the same as that for single injection. At $\theta_{1}=-30^{\circ}$ ATDC and $\theta_{2}=-5^{\circ} \mathrm{ATDC}$, the initial combustion is salient in both combustion chambers. The heat release rate of 
D52A is undoubtedly higher compared to D58A. The differences between the heat release rates provide the reasons for the tendencies of the THC and thermal efficiency. This is because the higher heat release rate means more natural gas is used for combustion.

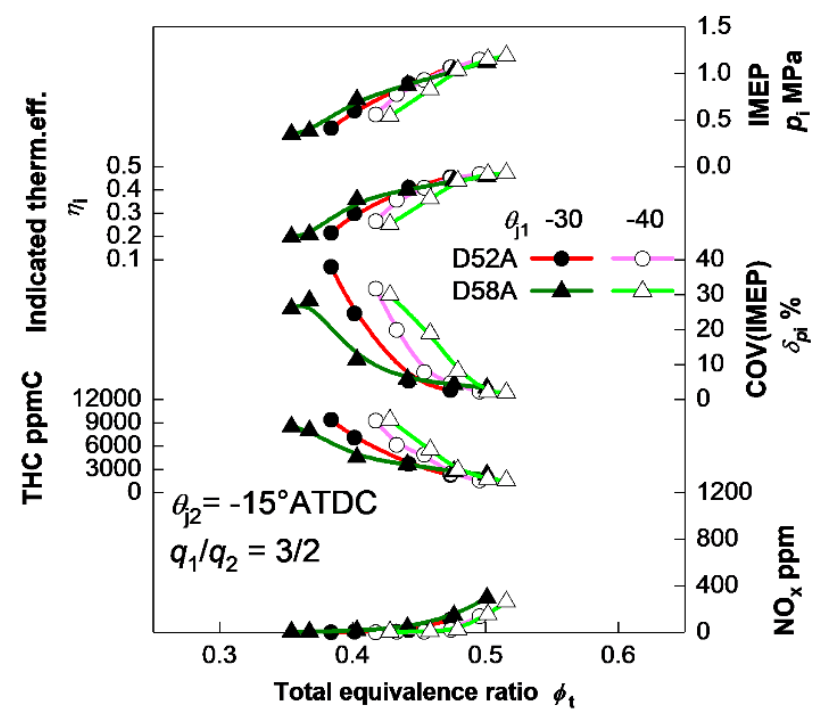

(a)

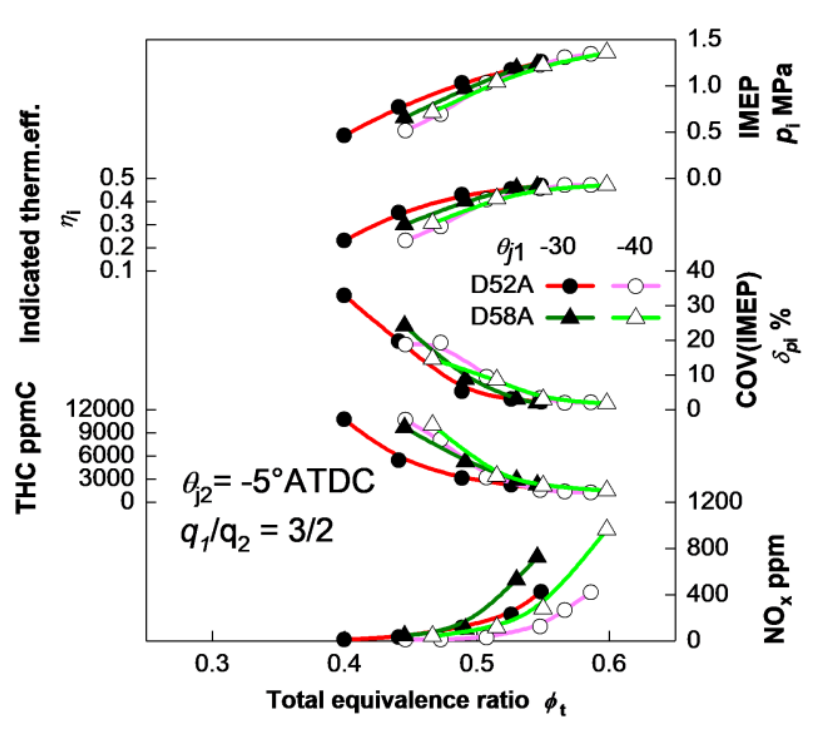

(b)

Fig.9 Performance and emissions against $\phi_{\tau}$ (twostage injection, $\theta_{22}=$ (a) $-15^{\circ}$ ATDC and (b) $-5^{\circ}$ ATDC)

\section{CFD RESULTS}

To elucidate the effect of pilot fuel distribution, CFD calculations for both the combustion chambers were conducted for non-reacting pilot fuel sprays under conditions equivalent to the experiments.

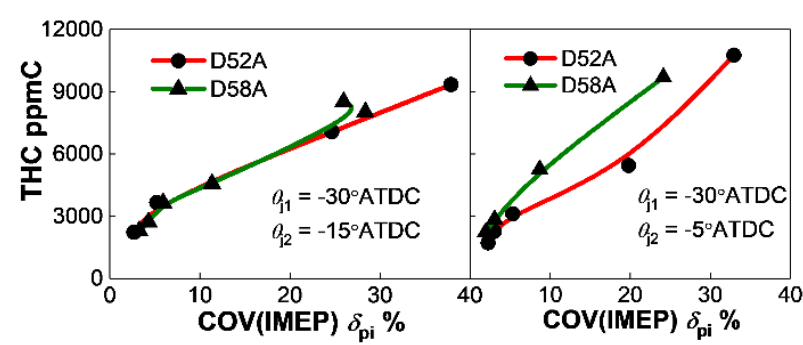

Fig.10 Relationship between $\delta_{\mathrm{pi}}$ and THC (two-stage injection)

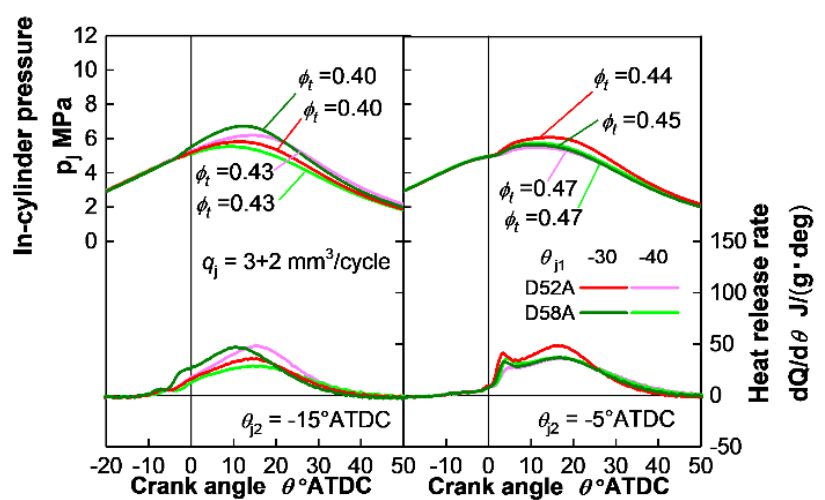

Fig.11 In-cylinder pressure and heat release rate at lower $\phi_{t}$ (two-stage injection) left: $\theta_{2}=$ $-15^{\circ}$ ATDC, right: $\theta_{2}=-5^{\circ}$ ATDC

To examine the spatial distribution of the pilot fuel, the calculated distributions of the mixture fraction $f$ were analyzed. Where $f$ is defined by the following equation:

$$
f=m_{\mathrm{pf}} /\left(m_{\mathrm{pf}}+m_{\mathrm{sg}}\right)
$$

and $m_{\mathrm{pf}}$ is the pilot fuel mass, and $m_{\mathrm{sg}}$ is the mass of the surrounding gas. If the surrounding gas is air, $f=$ 0.065 corresponds to an equivalence ratio of 1.0 .

\section{Single injection}

The injection timing of $-15^{\circ}$ ATDC was focused on. At first, cross-sections of the $f$ are shown in Figure 12. The cross-section indicates a conical surface including all the spray axes, as shown in Figure 13. As shown in Figure 7 left, combustion began just before TDC. Therefore, the pilot fuel distribution just before TDC is focused on and the distribution from $-7.0^{\circ}$ ATDC to $-1.0^{\circ}$ ATDC is shown in Figure 12. The sprays in D52A already impinged on the cavity wall at $-7^{\circ} A T D C$, and there are high $f$ areas near the wall. While for D58A, the pilot sprays did not yet impinge on the wall at $-7^{\circ} \mathrm{ATDC}$ because of the long distance from the nozzle to the wall, then the spray reached the wall after $-5.5^{\circ}$ ATDC. The sprays proceeded, distributed by a swirl flow, in particular, the spray in D52A seemed to be more affected due to the strong swirl flow by the small-diameter cavity.

In order to examine the effect of combustion chamber geometry on the mixing of pilot fuel and air, histograms 


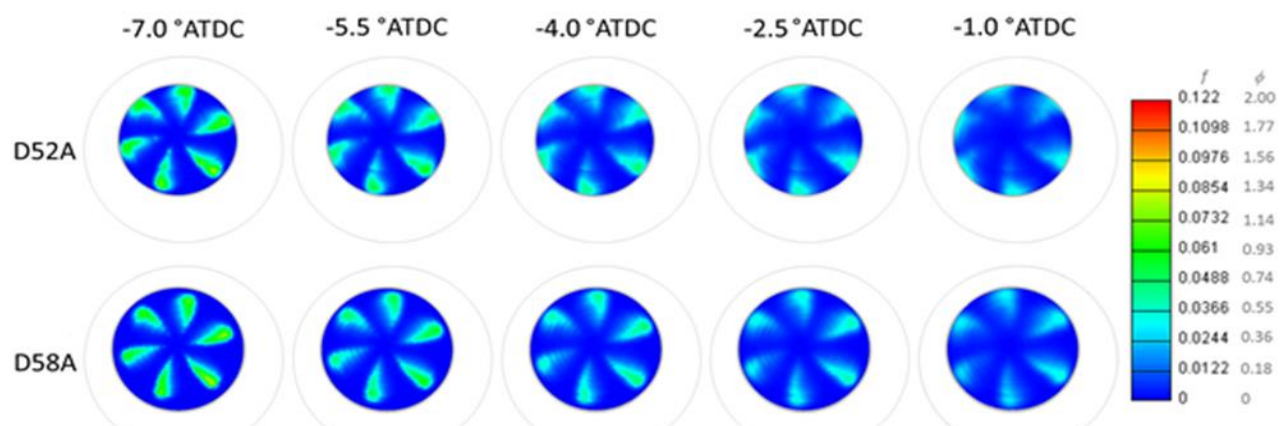

Fig.12 Distribution of diesel fuel mass fraction on a cross-sectional surface $\left(\theta=-15^{\circ}\right.$ ATDC $)$

of the mixture fraction of pilot fuel were calculated.

Figure 14 shows the histograms at $-2.5^{\circ}$ ATDC and $-5.5^{\circ} \mathrm{ATDC}$. These timings are the ignition timings of $\phi t$ $\approx 0.4$ and 0.5 , respectively

At $-5.5^{\circ}$ ATDC, the maximum $f$ was about 0.06 , while the maximum $f$ at $-2.5^{\circ}$ ATDC was 0.04 . Contrary to expectation, there were not significant differences due to the change of the combustion chamber geometry.

As described above, the ignition timing was advanced by the higher equivalence ratio. This indicates that the pilot fuel ignites when the relatively rich pilot fuel mixture remains, also before the effect of the swirl flow is increased. Therefore, the heat release rates of the initial combustion are salient, and the heat release rates of the main combustion are similar. In contrast, the ignition timing of the lower $\phi_{t}$ was delayed in comparison to the higher $\phi_{\mathrm{t}}$. Therefore, the spatial pilot fuel distribution in two combustion chamber geometries was different, as shown in Figure 12, although the histograms of the mixture fraction are not much different.

In order to determine where the higher $f$ is, Figure 15 shows the isosurface of the pilot fuel mixture fraction 0.035 at $-2.5^{\circ} \mathrm{ATDC}$. The value for the isofurface was set to easily understand the relative rich region in this case. The rich regions at $-2.5^{\circ} \mathrm{ATDC}$ reached the wall in D52A, whereas in the D58A they did not reach the wall. Therefore, a reason for the higher heat release rate of D58A could be due to the weak cooling effect to the rich regions. However, further investigation is needed to clarify the reasons why the heat release rate is influenced by the combustion chamber in the future.

\section{Two-stage injection}

CFD simulation for two-stage injection was also conducted. Figure 16 shows the histograms at each ignition timing. The left of each figure shows the histogram at a lower $f(f=0 \sim 0.02)$. In these figures, the differences between D52A and D58A are mainly caused by the distribution of the first injection. The right of each figure shows the histogram at a higher $f$. In these figures, the differences between D52A and D58A were mainly caused by the distribution of the second injection.

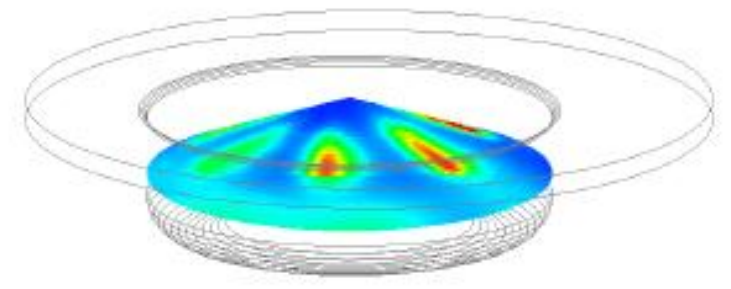

Fig.13 Conical surface for cross-sectional view

Focusing on the left figures, the high $f$ remains in D52A. This is because the wall impingement of the spray restrains the entrainment of the surrounding gas. In the right figures for $\theta_{2}=-5^{\circ} \mathrm{ATDC}$, (a) and (c), the differences between the two chambers were very small owing to the short mixing duration. Therefore, the heat release rates of the main combustion of D52A in the experiments were higher compared to D58A. Whereas, for $\theta_{2}=-15^{\circ} \mathrm{ATDC}$, (b) and (d), the difference in the histogram appears due to the long mixing duration. The high $f$ in D58A remains owing to the slower swirl flow, which leads to the higher heat release rates of D58A in the experiments compared to that of D52A. However, the above explanation is not enough for the higher heat release rate of D58A of $\theta_{1} / \theta_{2}=$ $-30 /-15^{\circ}$ ATDC. In this condition, the interval of the first and second injection timings is short. Therefore, the pilot fuel mixture of the first and second injections might interact. More detailed research is needed to examine the effects of the combustion chamber geometry on the pilot fuel mixture distribution of the two-stage injection in future, including the CFD simulation with combustion.

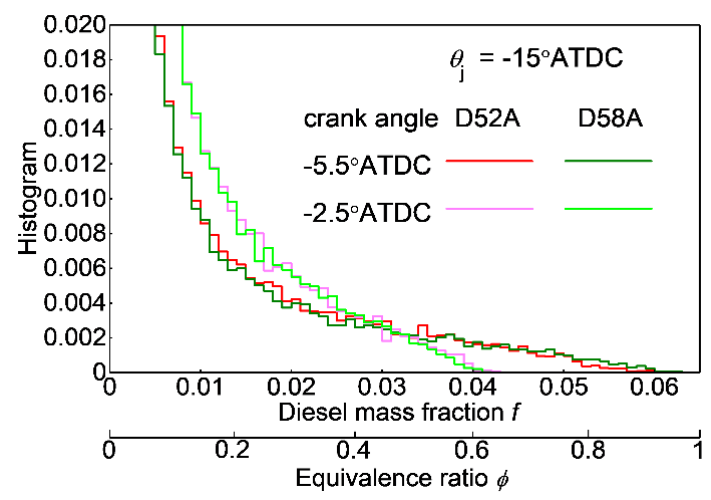

Fig.14 Histograms for diesel fuel mass fraction at $-5.5^{\circ} \mathrm{ATDC}$ and $-2.5^{\circ} \mathrm{ATDC} \quad(\theta \quad=$ $-15^{\circ} \mathrm{ATDCl}$ 
Fig.15 Isosurface for diesel fuel mixture fraction at $-2.5^{\circ} \mathrm{ATDC}\left(\theta=-15^{\circ} \mathrm{ATDC}, f=0.035\right)$
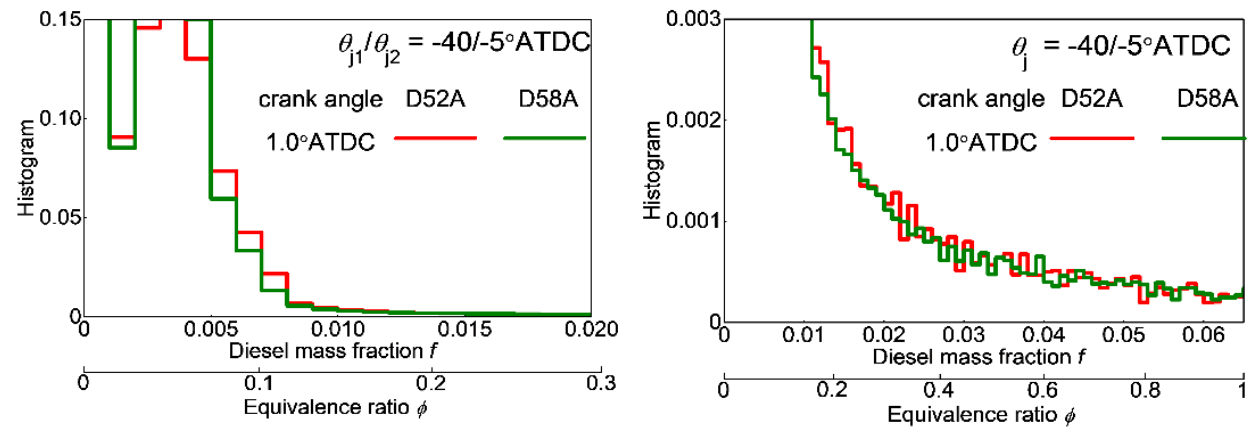

(a) $\theta_{1}=-40^{\circ} \mathrm{ATDC}, \theta_{2}=-5^{\circ} \mathrm{ATDC}$
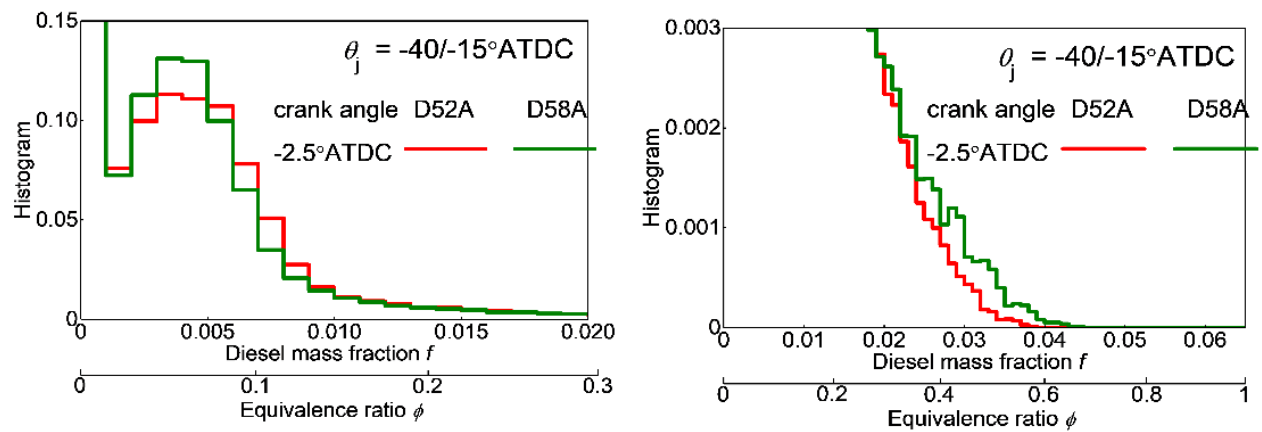

(b) $\theta_{1}=-40^{\circ}$ ATDC, $\theta_{2}=-15^{\circ}$ ATDC
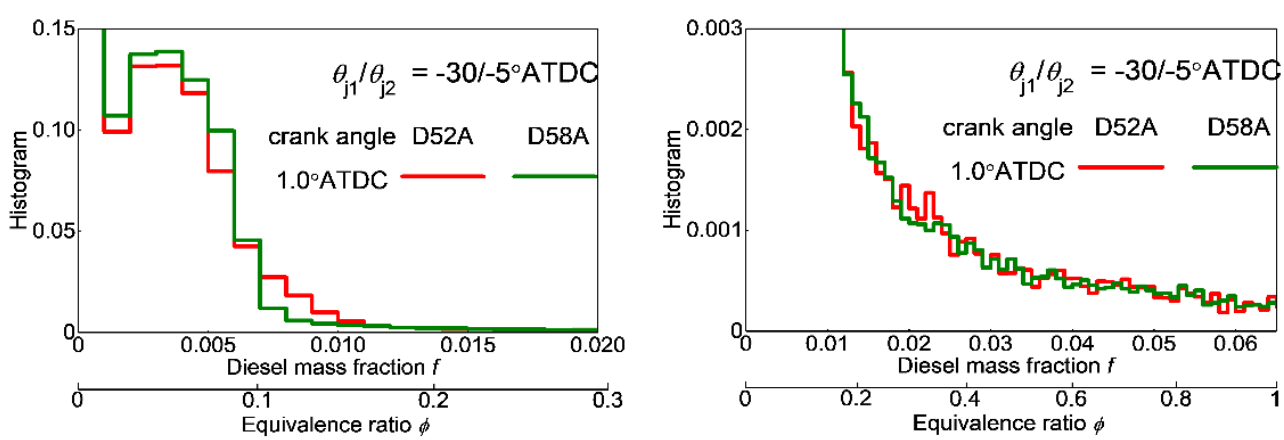

(c) $\theta_{1}=-30^{\circ} \mathrm{ATDC}, \theta_{2}=-5^{\circ} \mathrm{ATDC}$
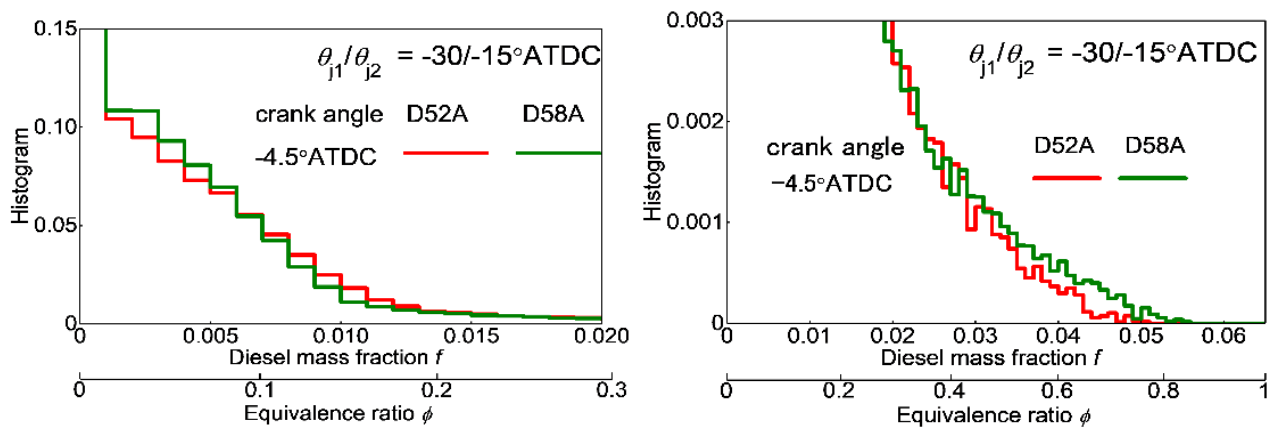

(d) $\theta_{1}=-30^{\circ}$ ATDC, $\theta_{2}=-15^{\circ}$ ATDC

Fig. 16 Histograms for diesel fuel mass fraction at different ignition timings 


\section{CONCLUSION}

In order to develop a strategy for designing the combustion chamber geometry of a natural gas/diesel dual fuel engine, the effect of the piston-cavity diameter was investigated using a single cylinder test engine. Moreover, a CFD simulation was conducted for non-reacting pilot fuel sprays to elucidate the pilot fuel distribution in the combustion chamber. The following conclusions can be drawn from the results:

1. Under relatively high equivalence ratio conditions $\left(\phi_{t}>0.4\right)$, the combustion chamber geometry does not significantly influence the THC emissions and thermal efficiency. However, under lower equivalence ratio conditions $\left(\phi_{t}<0.4\right)$, the largediameter combustion chamber (D58A) provides lower THC emissions and higher thermal efficiency in the case of single pilot injection $\left(\theta_{1}=-15^{\circ}\right.$ ATDC and $-5^{\circ}$ ATDC).

2. In the case of two-stage pilot injection, the smalldiameter combustion chamber is desirable for low THC emissions and high thermal efficiency under low equivalence ratio conditions $\left(\phi_{t}<0.4\right)$ except for the condition that first injection timing is $-30^{\circ}$ ATDC and second injection timing is $-15^{\circ} \mathrm{ATDC}$.

3. Based on the CFD simulation for single-stage injection, the pilot fuel distributions in both combustion chambers were not considerably different at the timing that the ignition occurs in the experiments under high equivalence ratio conditions. In contrast, under a low equivalence ratio, the spatial pilot fuel distribution in the two combustion chamber geometries is different at different ignition timings.

4. According to the CFD simulation for two-stage injection, the short impinging distance of D52A slows the mixing of the first pilot fuel, which is a reason for the high heat release rate of the main combustion of D52A.

\section{REFERENCES}

1. Fritz, S., and Egbuonu, R., "Emissions from Heavy-Duty Trucks Converted to Compressed Natural Gas," SAE Technical Paper No. 932950, 1993.

2. Kusaka, J., Okamoto T., Daisho Y., Kihara R., and Saito, T., "Combustion and Exhaust Emissions Characteristics of a Diesel Engine Fueled with Natural Gas," JSAE Review 21(4):pp.489-496, 2000.

3. Ishiyama, T., Shioji, M., Mitani, S., and Shibata, H. et al., "Improvement of Performance and Exhaust Emissions in a Converted Dual-Fuel Natural Gas Engine," SAE Technical Paper No. 2000-01-1866, 2000.

4. Karim,G.A., "An Examination of Some Measures for Improving the Performance of Gas Fuelled Diesel Engines at Light Load," SAE Transactions 100(4):966-974, 1991.
5. Tomita, E., Kawahara, E., Piao, Z., and Yamaguchi, R., "Effects of EGR and Early Injection of Diesel Fuel on Combustion Characteristics and Exhaust Emissions in a Methane Dual FuelEngine," SAE Technical Paper No. 2002-01-2723, 2002.

6. Aroonsrisopon, T., Salad, M., Wirojsakunchai, E., and Wannatong, K. et al., "Injection Strategies for Operational Improvement of Diesel Dual Fuel Engines under Low Load Conditions," SAE Technical Paper No. 2009-01-1855, 2009.

7. Ishiyama, T., Kang, J., Ozawa, Y., and Sako, T., "Improvement of Performance and Reduction of Exhaust Emissions by Pilot-Fuel-Injection Control in a Lean-Burning Natural-Gas Dual-Fuel Engine," SAE Int. J. Fuels Lubr. 5(1):243-253, 2012.

8. Amir-Hasan, K., Ali, N., Babak, P., and Amin P., "Effects of piston bowl geometry on combustion and emissions characteristics of a natural gas/diesel RCCl engine," Apllied Thermal Engineering 102:1462-1472, 2016, (in Japanese).

9. Kang, J., Ozawa Y., Ogata, T., Ishiyama, T., and Sako, T., "Effects of Injection Conditions and Combustion Chamber Geometry on Performance Emissions of a Natural-Gas Dual Fuel Engine," JSAE Transactions 43(2):473-478, 2012. (In Japanese)

10. Bao, Z., Horibe, N., and Ishiyama, T., "A Study of Diesel Spray Characteristics for Small-Quantity Injection," SAE Technical Paper 2018-01-0283, 2018.

\section{CONTACT}

Keigo Takizawa

takizawa.keigo.77v@st.kyoto-u.ac.jp

Naoto Horibe, Ph.D., Assistant Professor

horibe@energy.kyoto-u.ac.jp

Takuji Ishiyama, Ph.D., Professor

ishiyama@energy.kyoto-u.ac.jp 